DEPARTMENT OF ECONOMICS

Working Paper Series

Does Exposure to Unawareness Affect Risk Preferences? A Preliminary Result

Wenjun Ma

College of Economics, Shenzhen University

Burkhard Schipper

Department of Economics, University of California, Davis

May 25, 2016

Paper \# 16-2

One fundamental assumption often made in the literature on unawareness is that risk preferences are invariant to changes of awareness. We study how exposure to unawareness aects choices under risk. Participants in our experiment choose repeatedly between varying sure outcomes and a lottery in 3 phases. All treatments are exactly identical in phase 1 and phase 3 , but dier in phase 2 . There are ve dierent treatments pertaining to the lottery faced in phase 2 : The control treatment (i.e., a standard lottery), the treatment with awareness of unawareness of lottery outcomes but known number of outcomes, the treatment with awareness of unawareness of outcomes but with unknown number of outcomes, the treatment with unawareness of unawareness of some outcomes, and the treatment with an ambiguous lottery. We study both whether behavior diers in phase 3 across treatments (between subjects eect) and whether dierences of subjects' behavior between phases 1 and phase 3 diers across treatments (within subject eects). We observe no signi cant treatment eects.

Department of Economics One Shields Avenue

Davis, CA 95616

(530)752-0741

http://wp.econ.ucdavis.edu/ 


\title{
Does Exposure to Unawareness AfFect Risk Preferences? A Preliminary Result*
}

\author{
Wenjun $\mathrm{Ma}^{\dagger} \quad$ Burkhard C. Schipper
}

May 8, 2016

\begin{abstract}
One fundamental assumption often made in the literature on unawareness is that risk preferences are invariant to changes of awareness. We study how exposure to unawareness affects choices under risk. Participants in our experiment choose repeatedly between varying sure outcomes and a lottery in 3 phases. All treatments are exactly identical in phase 1 and phase 3 , but differ in phase 2 . There are five different treatments pertaining to the lottery faced in phase 2: The control treatment (i.e., a standard lottery), the treatment with awareness of unawareness of lottery outcomes but known number of outcomes, the treatment with awareness of unawareness of outcomes but with unknown number of outcomes, the treatment with unawareness of unawareness of some outcomes, and the treatment with an ambiguous lottery. We study both whether behavior differs in phase 3 across treatments (between subjects effect) and whether differences of subjects' behavior between phases 1 and phase 3 differs across treatments (within subject effects). We observe no significant treatment effects.
\end{abstract}

Keywords: Unawareness, Awareness of unawareness, Risk aversion, Experiments.

JEL-Classifications: C91, C92, D81, D87.

${ }^{*}$ We thank Friederike Mengel, Elias Tsakas, and Yoram Halevy as well as participants in the 2016 Bay Area Behavioral and Experimental Economics Workshop at Berkeley for helpful comments. Moreover, we gratefully acknowledge financial support by the Department of Economics, University of California, Davis.

${ }^{\dagger}$ College of Economics, Shenzhen University, Email: wenjunma@szu.edu.cn

${ }^{\ddagger}$ Department of Economics, University of California, Davis, Email: bcschipper@ucdavis.edu 


\section{Introduction}

The economics literature assumes that risk preferences do not change when perceiving new information. While this assumption may be justified when receiving standard information that is perfectly anticipated and foreseen, it is less compelling when conceiving of novel facts of which the decision maker was previously unaware. Unawareness refers more fundamentally to the lack of conception rather than the lack of information (see Schipper, 2015, for a survey). Nevertheless the literature on unawareness also assumes that risk preferences are not affected by changes of awareness. For instance, all approaches to extensive-form games with unawareness in the literature (Feinberg, 2012, Grant and Quiggin, 2013, Halpern and Rêgo, 2014, Heifetz, Meier, and Schipper, 2013b; see Schipper, 2014, for a nontechnical review) assume implicitly that utilities associated with terminal histories are unaffected by awareness. ${ }^{1}$ In work on updating under changes of awareness by Karni and Vierø $(2013,2015)$ the assumption of risk preferences being invariant to changes of awareness is the key axiom for linking preferences before and after becoming aware. Schipper (2013) characterizes awareness-dependent subjective expected utility theory with and without the assumption of invariant risk preference. All applications of unawareness in the literature (e.g., Auster, 2013, Li, Peitz, and Zhao, 2014, Maskin and Tirole, 1999, Schipper and Woo, 2015, von Thadden and Zhao, 2012) implicitly assume that risk preferences are invariant to awareness.

In this paper we report on a preliminary test of this assumption. We conduct an experiment in which we first measure participants' certainty equivalents for a lottery in phase 1 , then expose participants to lotteries with various degrees of unawareness of outcomes (depending on the treatment) in phase 2 , and then in phase 3 we remeasure participants' certainty equivalents for the first lottery. This design allows us to test the null-hypotheses that certainty equivalents do not differ between treatments (of various forms of unawareness) and within subjects (after being exposed to various forms of unawareness). Somewhat to our surprise, we cannot reject the null-hypotheses in our data.

One challenge of exposing participants to lotteries with unawareness of outcomes is how to describe the information about likelihood of outcomes to participants since probabilities must add up to one. We circumvent this difficulty by specifying the relative likelihood of outcomes of which participants aware of rather than probabilities. That is, instead saying that this or that outcome has such and such probability, we say that this outcome is $x$-times as likely as that outcome.

Our design allows us to study various notions of unawareness. Besides unawareness (i.e., Fagin and Halpern, 1988, Heifetz et al., 2006), we also consider versions of awareness of un-

\footnotetext{
${ }^{1}$ More precisely, extensive-form games with unawareness consist of a forest of trees that represent partial descriptions of the most comprehensive tree. It is assumed that the payoff of the terminal node of a less expressive tree corresponds to a payoff of the corresponding terminal node in the more expressive tree.
} 
awareness. This is relevant because in many circumstances a decision maker may realize that she is unaware of something. Awareness of unawareness has been epistemologically studied by Ågotnes and Alechina (2007), Board and Chung (2011), Halpern and Rêgo (2009, 2013), Sillari (2008) and Walker (2014) (see Schipper, 2015, for a survey). We consider two versions of awareness of unawareness. In the first version, the decision maker realizes that she is unaware of some outcomes and does not know how many outcomes there could be. In the second version of awareness of unawareness, the decision maker realizes that she is unaware of some outcomes and knows exactly how many outcomes she is unaware of. The latter version of awareness of unawareness has been implicitly used in the literature on incomplete contracting by Maskin and Tirole (1999) who assume that agents may not foresee physical contingencies but are able to foresee exactly the number of contingencies (see Ma and Schipper, 2015, for an extension to asymmetric information). Karni and Vierø (2015) study subjective expected utility under awareness of unawareness and changes thereof. Again, the assumption that risk preferences are invariant to changes of awareness is their key axiom for linking preferences before and after changes of awareness. We also add a treatment with just ambiguity, i.e., in which the probability distribution over outcomes is not completely specified, in order to find out whether the effect of exposure to ambiguity on risk preferences is different from the effect of exposure to various notions of unawareness on risk preferences.

We are not the first ones who attack experimentally the question of whether risk preferences are invariant to exposure of varying degrees of ignorance. We were inspired by Mengel, Tsakas, and Vostroknutov (2015). They present an experiment in which participants first choose between a fixed lottery and varying sure outcomes. There are three treatments that differ in the amount of information available about the lottery. In a second phase, which is identical in all treatments, participants choose between different lotteries and sure outcomes with all information available. The main finding is that participants who have been exposed to imperfect information become more risk averse in the second task. We discuss the similarities and differences between their and our experiment in Section 5.

The paper is organized as follows. The next section presents the hypotheses, which is followed by the exposition of the experimental design in section 3. Our results are reported in Section 4 and subsequently discussed in Section 5. An Appendix collects further details on the experiment such as instructions, screenshots and some additional analysis.

\section{Hypotheses}

We assume that participants have a von Neumann-Morgenstern utility both before and after being exposed to unawareness. Let $X$ be a finite set of monetary prizes. A lottery $p$ is a probability distribution over $X$. Given the set of lotteries $\Delta(X)$, decision maker $i$ has a preference relation $\succeq_{i}$ on $\Delta(X)$ that satisfies completeness, transitivity, continuity, and independence if 
and only if there exists a utility function $u_{i}: X \longrightarrow \mathbb{R}$ such that for any $p, q \in \Delta(X), p \succeq_{i} q$ if and only if $U_{i}(p)=\sum_{x \in X} u_{i}(x) p(x) \geq U_{i}(q)=\sum_{x \in X} u_{i}(x) q(x)$. The certainty equivalent $c_{i}(p)$ of decision maker $i$ for lottery $p$ is defined by $u_{i}\left(c_{i}(p)\right)=U_{i}(p)$. It is the amount of money that makes the decision maker indifferent between accepting that amount or the lottery.

We like to compare preferences of decision makers for the same set of well-specified lotteries before (i.e., phase 1) and after (i.e., phase 3 ) being exposed to unawareness. We denote by $c_{i}^{1}(p)$ and $c_{i}^{3}(p)$ the certainty equivalents for lottery $p$ before and after being exposed to unawareness.

Following standard terminology (Pratt, 1964), we say that decision maker $i$ is more risk averse after being exposed to unawareness if for all $p \in \Delta(X), c_{i}^{3}(p) \leq c_{i}^{1}(p)$, that is if she accepts a smaller certainty equivalent after being exposed to unawareness. It follows from Pratt (1964) that a decision maker is more risk averse after exposure to unawareness if and only if whenever she prefers the lottery over some certain outcome after being exposed to unawareness, she must also prefer it before being exposed to unawareness.

We consider the particular lottery $p$ (given in Table 1) both in phases 1 and 3 . By letting participants in the experiment choose repeatedly between this lottery and various sure payments, we can approximate participant $i$ 's certainty equivalents $c_{i}^{1}(p)$ and $c_{i}^{3}(p)$ in phases 1 and 3 , respectively. Our treatments involve exposing subjects to varying degrees of unawareness (see the next section) in phase 2. Our null-hypotheses are as follows:

Hypothesis 1 (Between-subjects) The certainty equivalents in phase 3, $c_{i}^{3}(p)$, do not differ across treatments.

Hypothesis 2 (Within-subjects) The differences of certainty equivalents of phases 1 and 3, $c_{i}^{1}(p)-c_{i}^{3}(p)$, do not differ from zero across treatments.

Note that if we reject the null hypotheses then there is very strong evidence that risk preferences are affected by unawareness. If we do not reject the null hypotheses then we cannot conclude that risk preferences are not affected by unawareness. This is because we just compare one lottery and its certainty equivalent. That is, if we cannot reject the null-hypotheses then at best this may be taken as evidence that "locally" (i.e., for some lotteries) subjects behave as if risk preferences are unaffected by unawareness. It may well be the case that for some other lottery the participant's certainty equivalent may be affected by unawareness. Clearly, it would be infeasible to design an experiment involving all lotteries in $\Delta(X)$. So the current approach may be understood as a preliminary test. See Section 5 for further discussions. 


\section{Experimental Design}

Participants were recruited from the campus of the University of California, Davis, using the ORSEE recruitment system by Greiner (2004). This experiment was advertised as "a lab experiment on decision-making" mostly via emails from undergraduate coordinators, graduate coordinators and teaching assistants. All treatments were programmed in z-tree (Fischbacher, 2007). All sessions were conducted in computer classrooms on the campus of the University of California, Davis, between May 18 and 26, 2015.

Upon arrival at the computer classroom, participants were seated randomly at computer terminals. Participants were given consent forms to read and sign. Participants were also given instructions to read (see Appendix A.1). An experimenter then collected the signed consent forms. At every session, the same experimenter was present to explain the instructions. After making sure there was no question about the experiment, experimenters started z-tree program, and participants made their choices on computers. Once finished with the choices on the computer, each participant was handed a paper questionnaire by the experimenter to fill in. At the end of the experiment, experimenters called participants by their computer terminal numbers one-by-one to issue the money payments, and also collected the filled-in questionnaires.

The experiment consisted of 3 phases, in each phase there were 16 periods. Altogether there were 48 periods. Phase 1 comprised of periods 1 to 16, phase 2 of periods 17 to 32 , and phase 3 of periods 33 to 48. In each period, participants chose between a lottery and a sure payment. The sure payment varied from period to period. When a lottery was chosen by the participant, then lottery was played out immediately. The realizations were generated independently for each participant. The realized outcome of the lottery was immediately displayed to the participant, and such outcome was the reward of that period. If the sure payment was selected by the participant, the sure payment was the reward of that period, and the lottery was not played out.

Table 1 represents the lottery in phase 1 and phase 3 . The lottery has five outcomes. The expected value of the lottery is $\$ 13.39$, and the standard deviation is 5.07 . The sure payments vary in random order from $\$ 9.00$ to $\$ 16.50$ with a $\$ 0.50$ interval. Participants observed both outcomes as well as associated relative likelihoods in all periods in phase 1.

In the instruction of the experiment, we illustrated the meaning of relative likelihoods with a bar chart. Actual screenshots from the experiment are shown in Appendix A.3.

Table 1: Lottery in phase 1

\begin{tabular}{|c||c|c|c|c|c|}
\hline Outcomes & $\$ 0$ & $\$ 4$ & $\$ 13$ & $\$ 14$ & $\$ 21$ \\
\hline Relative Likelihoods & 1 & 2 & 8 & 8 & 4 \\
\hline
\end{tabular}


To emphasize, in the entire experiment, phase 3 was identical to phase 1 . That is, the lotteries in phase 3 were the same as the lottery in phase 1 , and the sure payments in phase 3 occurred in the same random order as in phase 1 . But the random order of sure payments varied independently among participants.

There are 5 treatments in total. All treatments are identical in phases 1 and 3 . They just differ in phase 2. The difference is the amount of information provided to the subjects about the lottery in phase 2 . In phase 2 , the lottery is different from phase 1 and phase 3 , but it still has five outcomes. Table 2 represents the lottery in phase 2. The expected value of the lottery is $\$ 13.00$, and the standard deviation is 7.18 . The sure payments vary from $\$ 9.00$ to $\$ 16.50$ with a $\$ 0.50$ interval, the same as in phase 1 and 3 .

Table 2: Lottery in phase 2

\begin{tabular}{|c||c|c|c|c|c|}
\hline Outcomes & $\$ 0$ & $\$ 8$ & $\$ 14$ & $\$ 20$ & $\$ 25$ \\
\hline Relative Likelihoods & 6 & 6 & 12 & 12 & 1 \\
\hline
\end{tabular}

In phase 2 of Treatment $C$ (control treatment), there was perfect information about the lottery. That is, both the five outcomes and the relative likelihoods of each outcome were described to participants.

Treatment $U$ (treatment with unawareness of unawareness) is the focus of our experiment. In phase 2 of Treatment U, participants were initially aware of a subset of outcomes of the lottery, i.e., $\$ 14.00, \$ 20.00$, and $\$ 25.00$, and their relative likelihoods. They were unaware of the existence of further outcomes. They may discover further outcomes during phase 2. If the lottery was chosen by participants, and the realized outcome was previously hidden, i.e., $\$ 0.00$ (or \$8.00), there was a notice in red color displayed on the screen: "Surprise! The lottery has actually another possible payment of $\$ 0.00$ (or $\$ 8.00$ ), which was not described on the previous page!" Moreover, this outcome and its relative likelihood were displayed in later periods. Appendix A.3 presents actual screenshots for the treatment.

Note that Treatment $U$ would be impossible to conduct if lotteries were presented with probabilities instead of relative likelihoods. We use relative likelihood rather than probabilities as it allows us to also quantify uncertainty for outcomes even in case when not all outcomes of the lottery is disclosed, which is not only relevant for Treatment $U$ but also for the next two treatments discussed.

In phase 2 of Treatment AU1 (treatment with awareness of unawareness of outcomes and with known number of outcomes), participants were initially aware of a subset of outcomes, i.e., $\$ 14.00, \$ 20.00$, and $\$ 25.00$, and their relative likelihoods. In contrast to treatment $\mathrm{U}$, they were also aware that there were hidden outcomes. Each hidden outcome and its relative likelihood were represented by a column of question marks "?" (see Figure 6 in Appendix A.3). Therefore, 
they knew that the total number of outcomes was five. Similar to Treatment U, if the lottery was chosen by participants, and the hidden outcome was realized, there was a notice in red color displayed on the screen: "Surprise! The lottery has actually another possible payment of $\$ 0.00$ (or $\$ 8.00$ ), which was not described on the previous page!" Moreover, this outcome and its relative likelihood were displayed in later periods. Appendix A.3 presents actual screenshots for the treatment.

In phase 2 of Treatment AU2 (treatment with awareness of unawareness of outcomes and with unknown number of outcomes), participants initially were aware of the same subset of outcomes, i.e., $\$ 14.00, \$ 20.00$, and $\$ 25.00$, and their relative likelihoods. They also were aware that there were hidden outcomes. Different from Treatment AU1, participants did not know the total number of outcomes. The hidden outcomes and associated relative likelihoods were represented as "?..." (see Figure 7 in Appendix A.3). As in treatments U and AU1, if the lottery was chosen by participants, and the hidden outcome was realized, there was a notice in red color displayed on the screen: "Surprise! The lottery has actually another possible payment of $\$ 0.00$ (or $\$ 8.00$ ), which was not described on the previous page!" Moreover, this outcome and its relative likelihood were displayed in later periods. As soon as both hidden outcomes were realized, the "?..." did not show in the lottery afterwards.

In phase 2 of Treatment $A$ (ambiguity treatment), participants knew the five outcomes of the lottery. Only the relative likelihoods associated with outcomes $\$ 14.00, \$ 20.00$, and $\$ 25.00$ were displayed to them but the relative likelihoods associated with $\$ 0.00$ and $\$ 8.00$ were not displayed, see Figure 8 in Appendix A.3 for a screenshot. This treatment features ambiguity or Knightian uncertainty.

At the end of the experiment participants were paid for one period only. This period was selected randomly and independently for every participant. The reward earned in such period and the show up fee were summed up to the final payments to participants. Participants were upfront informed about how their payments are calculated.

\section{Results}

The datasets and Stata do-file that reproduce the entire analysis reported here and additional analysis are available from http://www.econ.ucdavis.edu/faculty/schipper/.

We had 437 participants who took part in our experiment of 16 sessions in total. Each session took 45 to 55 minutes. The numbers of subjects in each session varied from 22 to 34 . On average, there were 27 subjects in each session. The show-up fee was $\$ 5.00$, and the final payment varied from $\$ 5.00$ to $\$ 30.00$. The mean of the final payments was $\$ 18.18$, and the standard deviation was 5.49 .

Table 3 shows numbers of subjects in each treatment. Table 4 summarizes the demographics 
of the data as elicited with the questionnaire (see Section A.2). ${ }^{2} 241$ participants (55\%) have taken a course in microeconomics, game theory, decision making, or economics of uncertainty before. Out of the 436 participants, 274 (63\%) are female. One subject did not provide gender or age information. Most of the subjects are asian-americans (62\%) followed by whites (29\%). Ten subjects did not provide information on their GPA.

Table 3: Number of subjects by treatment

\begin{tabular}{cc}
\hline Treatment & Number of subjects \\
\hline $\mathrm{C}$ & 108 \\
$\mathrm{U}$ & 82 \\
$\mathrm{AU} 1$ & 81 \\
$\mathrm{AU} 2$ & 86 \\
$\mathrm{~A}$ & 80 \\
\hline Total & 437
\end{tabular}

Table 4: Basic Demographics

\begin{tabular}{lccc}
\hline Variable & Number & Mean & Std. Dev. \\
\hline Female & 274 & 0.63 & \\
Age & & 21.24 & 3.25 \\
\hline White & 125 & 0.29 & \\
Asian & 271 & 0.62 & \\
Hispanic & 54 & 0.12 & \\
Black & 5 & 0.01 & \\
Other & 13 & 0.03 & \\
\hline Student & 435 & 0.99 & \\
Economic course & 241 & 0.55 & \\
GPA & 427 & 3.28 & 1.37 \\
\hline Maths and Statistics & 17 & 0.04 & \\
Sciences & 184 & 0.42 & \\
Economics & 108 & 0.25 & \\
Social Sciences & 102 & 0.23 & \\
Humanities & 23 & 0.05 & \\
\hline
\end{tabular}

To test whether risk preference differ between treatments, we regress participants' approximate certainty equivalents of phase 3 on dummies indicating treatments (with the control treatment as omitted variable) using OLS. Within each phase, we define each participant's approximate certainty equivalent as the average of the maximum sure payment foregone in favor of the lottery and the minimum sure payment accepted over the lottery. Note that this provides

\footnotetext{
${ }^{2}$ Subjects were allowed to select ethnic backgrounds. Thus, the means do not add up to unity. If multiple majors were selected, then the first major or economics-related major was picked.
} 
us with an approximate certainty equivalent even in case that the participant displays multiple switch points between sure payments and lottery. The results are presented in specification b1 in Table 5. We observe no significant difference between treatments (relative to the control treatment). To put the size of the coefficients into perspective, consider that the average approximate certainty equivalents are $\$ 7.06, \$ 6.90, \$ 7.35, \$ 6.62$, and $\$ 6.80$ in treatments $\mathrm{C}$, $\mathrm{U}, \mathrm{AU} 1, \mathrm{AU} 2$, and A, respectively. Thus, we don't believe that there is just lack of power. Similarly, in Table 6 we analyze how the change of certainty equivalents from phases 1 to 3 is affected by the treatments (with-in-subjects). Specification w1 in Table 6 shows that there are no significant treatment effects.

One potential problem is measurement error, which is known to produce an attenuation bias. In particular, quite a number of participants behave inconsistently with von NeumannMorgenstern utility theory in the sense that they display multiple switches between the lottery and sure payments. Table 7 presents for each treatment the fraction of participants who are consistent in phase 3 and the fraction of participants who are consistent both in phases 1 and 3. Consistency is not significantly different across treatments. See Table 8 in the Appendix for a probit regressions of consistency on treatments controlling for demographics.

Table 5: Certainty Equivalents in Phase 3

\begin{tabular}{lcccc}
\hline & $\mathrm{b} 1$ & $\mathrm{~b} 2$ & $\mathrm{~b} 3$ & $\mathrm{~b} 4$ \\
\hline Unawareness & 0.0362 & 0.1281 & -0.0780 & 0.1042 \\
& $(0.2579)$ & $(0.3577)$ & $(0.2539)$ & $(0.3616)$ \\
Awareness of unawareness 1 & -0.3185 & -0.3058 & -0.4342 & -0.4114 \\
& $(0.3093)$ & $(0.4349)$ & $(0.3052)$ & $(0.4283)$ \\
Awareness of unawareness 2 & 0.1833 & 0.4683 & 0.0080 & 0.2588 \\
& $(0.2346)$ & $(0.3021)$ & $(0.2213)$ & $(0.2896)$ \\
Ambiguity & 0.1849 & 0.2244 & 0.0459 & 0.1660 \\
& $(0.2357)$ & $(0.3186)$ & $(0.2386)$ & $(0.3231)$ \\
Questionnaire Controls & No & No & Yes & Yes \\
\hline Number of Observations & 431 & 263 & 421 & 260 \\
$\mathrm{R}^{2}$ & 0.0098 & 0.0171 & 0.1166 & 0.1232
\end{tabular}

Robust standard errors (clustered at the subject level) in parentheses. Significance levels: * $10 \%$; ** $5 \%$; *** $1 \%$

Specifications b2 in Table 5 shows that certainty equivalents also do not differ significantly across treatments when restricting regressions to participants who are consistent in phase 3 (between subjects). Specification $\mathrm{w} 2$ in Table 6 shows an analogous result for differences of certainty equivalents between phases 1 and 3 across treatments (in within-subjects). Of course, restricting to consistent participants reduces the number of observations.

Controlling for demographics, gpa, whether or not the participant took a course in economics, and how they answered questions on risk preferences and attitudes to novelty in the questionnaire (see Appendix A.2) still allows not to reject the null hypothesis no matter whether 
Table 6: Difference of Certainty Equivalents between Phase 1 and 3

\begin{tabular}{lcccc}
\hline & $\mathrm{w} 1$ & $\mathrm{w} 2$ & $\mathrm{w} 3$ & $\mathrm{w} 4$ \\
\hline Unawareness & -0.0586 & -0.0076 & -0.0201 & -0.0705 \\
& $(0.2225)$ & $(0.3538)$ & $(0.2277)$ & $(0.3691)$ \\
Awareness of unawareness 1 & -0.1531 & -0.5351 & -0.1712 & -0.6383 \\
& $(0.2677)$ & $(0.4290)$ & $(0.2766)$ & $(0.4660)$ \\
Awareness of unawareness 2 & 0.0941 & -0.1998 & 0.1097 & -0.3515 \\
& $(0.2156)$ & $(0.2373)$ & $(0.2175)$ & $(0.2575)$ \\
Ambiguity & -0.3006 & $-0.4933^{* * *}$ & -0.2409 & $-0.5759^{* * *}$ \\
& $(0.2035)$ & $(0.1459)$ & $(0.2054)$ & $(0.1661)$ \\
Questionnaire Controls & No & No & Yes & Yes \\
\hline Number of Observations & 431 & 138 & 421 & 137 \\
$\mathrm{R}^{2}$ & 0.0071 & 0.0260 & 0.0237 & 0.0789
\end{tabular}

Robust standard errors (clustered at the subject level) in parentheses.

Significance levels: $* 10 \%$; ** $5 \%$; *** $1 \%$

Table 7: Fraction of Consistent Participants

\begin{tabular}{lcc}
\hline Treatment & Phase 3 & Phases $1 \& 3$ \\
\hline Control & 0.61 & 0.32 \\
Unawareness & 0.61 & 0.34 \\
Awareness of unawareness 1 & 0.65 & 0.38 \\
Awareness of unawareness 2 & 0.60 & 0.28 \\
Ambiguity & 0.58 & 0.28 \\
\hline
\end{tabular}

we consider all participants (specifications b3 and w3 in Tables 5 and 6 , respectively) or restrict to consistent participants only (specifications b4 and w4 in Tables 5 and 6, respectively).

So far, the analysis focused on average approximate certainty equivalents. Figure 9 in the Appendix presents scatter plots which show tuples of approximate certainty equivalents of phases 1 and 3 by treatment. The size of the circles indicate the size of the frequency of each tuple. These figures do not suggest to us that there could be systematic differences among subgroups or quantiles between treatments.

We summarize the finding as follows:

Observation 1 (Between-subjects) We cannot reject the null-hypothesis that certainty equivalents in phase 3 do not differ across treatments.

Observation 2 (Within-subjects) We cannot reject the null-hypothesis that differences of certainty equivalents of phases 1 and 3 do not differ from zero across treatments. 


\section{Discussion}

Although one of the authors has been involved in the theoretical literature on unawareness and as such frequently assumed that risk preferences are invariant to unawareness, he always felt at unease with the assumption and did not believe that it would hold up in an experiment. That's why we intentionally designed a "weak" test of this assumption in the sense that if we were to reject the null-hypotheses this would be strong evidence that risk preferences are not invariant to exposure to unawareness. Ex ante expected that we can reject the invariance (especially with the result by Mengel, Tsakas, and Vostroknutov 2015, in mind; see below). To our surprise, as it turns out in our data, we were not able to reject the null-hypotheses use relative likelihood rather than probabilities as it allows us to also quantify uncertainty for outcomes even in case when not all outcomes of the lottery is disclosed, which is relevant for phase 2 that differs by treatments (see below). This does not mean, however, that we are ready to easily accept the null-hypothesis because our test is "weak". First of all, we did not reject the null-hypotheses given a particular lottery. It does not mean that there couldn't be other lotteries for which the null-hypothesis could be rejected. We plan to follow up on this in future research. Yet, we report our preliminary results here in order to commit ourselves to distinguish clearly between our ex ante and ex post hypotheses.

Second, the effect of unawareness in phase 2 may be too small. Participants in our experiments were just unaware of some positive monetary outcomes in a lottery. It is hard to believe that exposure to such unawareness, awareness of unawareness, and ambiguity by a lottery in a lab experiment is comparable to mind-changing, life-changing and transformative experiences that raise your awareness of important events. Indeed, field experiments suggest that lifechanging crises may affect risk preferences. Nishiyama (2006) claims that the Asian crisis of 1997 led to a persistent increase in US banks' risk aversion. Callen et al. (2014) and Kim and Lee (2014) claim that elicited risk aversion increases after exposure to violence or war. It is obvious that mind-changing experiences are hard to create in a lab environment. Yet, it may be already worthwhile to expose subjects to contexts in which they are unaware of negative payoffs in lotteries. This is left for future research.

Regarding the first point, Mengel, Tsakas, and Vostroknutov (2015) present an experiment in which they measure risk aversion using several lotteries. Their experiment consists of two phases. In the first phase, participants first choose between a fixed lottery and varying sure outcomes. There are three treatments that differ in the amount of information available about the lottery including one treatment where there is awareness of unawareness and participants do not know the number of outcomes they are unaware of. (This treatment corresponds most closely to our treatment Awareness of Unawareness 2). In the second phase of their experiment, which is identical in all treatments, participants choose between different lotteries and sure outcomes with all information available. The main finding is that participants who have been 
exposed to hidden information in the first phase seem to become more risk averse in the second task. Their design and analysis differs in some crucial points from ours. Obviously our design allows also for within-subjects analysis while their design does not allow this. On the other hand they could approximate certainty equivalents for various lotteries (which unfortunately they do not report) while we just focus one lottery. We use relative likelihood of outcomes in lotteries whereas they use probabilistic information or are simply silent on the probabilities of outcomes. Moreover, their analysis assumes either mean-variance preferences or CRRA preferences while we assume only von Neumann-Morgenstern preferences. Yet, what we think is most important is that in their design there are less outcomes of the lotteries in the second phase than in the first phase. In particular, lotteries in the second phase consist only of two outcomes whereas lotteries in the first phase involve seven outcomes with some being initially hidden depending on the treatment. Thus, participants may still expect in the second phase that some outcomes are hidden (simply because they were used to more outcomes before in phase 1 or depending on the treatment they experienced previously that some outcomes were hidden). Hence, they may behave more cautiously in phase 2 especially after treatments where information was hidden. If their positive result is indeed an artefact of this effect, then our design avoids this by having the same number of outcomes in all phases.

Lastly we like to comment on the nature of information provided to subjects in our unawareness treatment. Conducting experiments involving participants' unawareness of outcomes of the lottery makes is necessary to not disclose everything to participants. This is simply unavoidable. If we were to tell participants upfront that there could be outcomes of the lottery not previously described then we would already change the participants' mind as unawareness of unawareness would turn into awareness of unawareness. This is precisely the difference between our unawareness treatment and the treatment on awareness of unawareness 2. Not disclosing everything to participants in an experiment should not be confused with lying to participants. Every piece of information conveyed in the instructions is truthful and verifiable. We are just silent on some outcomes of the lottery. (In fact the information provided to participants is akin to the notion of information in games of verifiable information, e.g., Milgrom and Roberts, 1986.) In some sense in almost all economic experiment in the literature participants are not told literally everything about the experiment. Very often the very purpose of an experiment is concealed from participants for the fear that knowledge of the purpose may affect their behavior. Yet, we acknowledge that our experiment involves an unusual degree of non-disclosure. Similar to the effect of lying to participants, not disclosing everything that is relevant to the participants' decisions may lead them to mistrust our instructions in later experiments. We mitigate this by keeping track of who participated in which experiment using ORSEE (Greiner, 2004) and will exclude participants in the unawareness treatment from future experiments. It appears though that it did not affect behavior in the current experiment since we were unable to find significant differences between our treatments. 


\section{References}

[1] Ågotnes, T. and N. Alechina (2007). Full and relative awareness: A decidable logic for reasoning about knowledge of unawareness, in: D. Samet (Ed.), Proceedings of the 11th Conference on Theoretical Aspects of Rationality and Knowledge, Presses Universitaires De Louvain, 6-14.

[2] Auster, S. (2013). Asymmetric awareness and moral hazard, Games and Economic Behavior $82,503-521$.

[3] Board, O. and K.S. Chung (2011). Objective-based unawareness: Axioms, University of Minnesota.

[4] Callen, M., M. Isaqzadeh, J. Long, and C. Sprenger (2014). Violence and risk preference: Experimental evidence from Afghanistan, American Economic Review 104(1), 123-148.

[5] Fagin, R. and J. Halpern (1988). Belief, awareness, and limited reasoning, Artificial Intelligence $34,39-76$.

[6] Feinberg, Y. (2012). Games with unawareness, Stanford University.

[7] Fischbacher, U. (2007). z-Tree: Zurich toolbox for ready-made economic experiments, Experimental Economics 10(2), 171-178.

[8] Grant, S. and J. Quiggin (2013). Inductive reasoning about unawareness, Economic Theory $54,717-755$.

[9] Greiner, B. (2004). An online recruitment system for economic experiments, in: Kremer, K., Macho, V. (eds.), Forschung und wissenschaftliches Rechnen 2003. GWDG Bericht 63, Göttingen: Ges. für Wiss. Datenverarbeitung, 79-93.

[10] Halpern, J. and L.C. Rêgo (2009). Reasoning about knowledge of unawareness, Games and Economic Behavior 67, 503-525.

[11] Halpern, J. and L.C. Rêgo (2013). Reasoning about knowledge of unawareness revisited, Mathematical Social Sciences 66, 73-84.

[12] Halpern, J. and L.C. Rêgo (2014). Extensive games with possibly unaware players, Mathematical Social Sciences 70, 42-58.

[13] Heifetz, A., Meier, M., and B.C. Schipper (2013a). Unawareness, beliefs, and speculative trade, Games and Economic Behavior 77, 100-121.

[14] Heifetz, A., Meier, M., and B.C. Schipper (2013b). Dynamic unawareness and rationalizable behavior, Games and Economic Behavior 81, 50-68. 
[15] Heifetz, A., Meier, M., and B.C. Schipper (2006). Interactive unawareness, Journal of Economic Theory 130, 78-94.

[16] Karni, E. and M.-L. Vierø (2013). "Reverse Bayesianism": A choice-based theory of growing awareness, American Economic Review 103, 2790-2810. (2013)

[17] Karni, E. and M.-L. Vierø (2015). Awareness of unawareness: A theory of decision making in the face of ignorance, John Hopkins University.

[18] Kim, Y.-I. and J. Lee (2014). The long-run impact of a traumatic experience on risk aversion, Journal of Economic Behavior and Organization, 108, 174-186.

[19] Li S.X., Peitz, M., and Zhao X.J. (2014). Vertically differentiated duopoly with unaware consumers, Mathematical Social Sciences 70, 59-67.

[20] Ma W.J. and B.C. Schipper (2015). Indescribable contingencies versus unawareness in incomplete contracting, The University of California, Davis.

[21] Maskin, E. and J. Tirole (1999). Unforeseen contingencies and incomplete contracts, Review of Economic Studies 66, 83-114.

[22] Mengel, F., Tsakas, E., and A. Vostroknutov (2015). Past experience of uncertainty affects risk aversion, Experimental Economics, forthcoming.

[23] Milgrom, R. and J. Roberts (1986). Relying on the information of interested parties, Rand Journal of Economics 17, 18-32.

[24] Nishiyama, Y. (2006). The asian financial crisis and investors risk aversion, Asia-Pacific Financial Markets 13, 181-205.

[25] Pratt, J.W. (1964). Risk aversion in the small and in the large, Econometrica 32, 122-136.

[26] Schipper, B.C.(2013). Awareness-Dependent Subjective Expected Utility, International Journal of Game Theory 42, 725-753.

[27] Schipper, B.C. (2014). Unawareness - A gentle introduction to both the literature and the special issue, Mathematical Social Sciences 70, 1-9.

[28] Schipper, B.C. (2015). Awareness, in: Handbook of Epistemic Logic, Chapter 3, H. van Ditmarsch, J.Y. Halpern, W. van der Hoek and B. Kooi (Eds.), College Publications, London, 77-146.

[29] Schipper, B. C. and H.Y. Woo (2015). Political Awareness, microtargeting of voters and negative electoral campaigning, mimeo., The University of California, Davis. 
[30] Sillari, G. (2008). Quantified logic of awareness and impossible possible worlds, Review of Symbolic Logic 1, 514-529.

[31] von Thadden, E.-L. and Zhao X. J. (2012). Incentives for unaware agents, Review of Economic Studies 79, 1151-1174.

[32] Walker, O. (2014). Unawareness with possible possible worlds, Mathematical Social Sciences 70, 23-33. 
A Supplementary Appendix 


\section{A.1 Instructions}

\section{Instructions}

Thank you for participating in this experiment. You will receive at least a $\$ 5.00$ show up fee for your participation. You can earn additional money with the choices you make in the experiment. So please read the following explanations carefully.

During the experiment you are not allowed to communicate with each other. If you have any questions please raise your hand. An experimenter will come to answer your questions.

The experiment consists of 3 phases, in each phase there are 16 periods. Altogether there are 48 periods. In each period you will choose between a lottery and a sure money payment. In each phase, the lottery is the same in all periods but the sure money payment may vary from period to period. However, the lotteries can be different between phases.

Here is an example of one period in phase 1:

\begin{tabular}{|c|c|c|}
\hline \multicolumn{3}{|c|}{ Lottery } \\
\hline$\$ 2.00$ & $\$ 5.00$ & $\$ 7.00$ \\
\hline & 4 times as likely as & 2 times as likely as \\
& $\$ 2.00$ payment & $\$ 2.00$ payment \\
\hline
\end{tabular}

\begin{tabular}{|c|}
\hline Sure money payment \\
\hline$\$ 4.50$ \\
\hline
\end{tabular}

In this example, if you choose the sure money payment you will receive $\$ 4.50$. If you choose the lottery then you might receive $\$ 2.00$, $\$ 5.00$, or $\$ 7.00$. Below each possible payment, we write how likely it is relative to the $\$ 2.00$ payment. For example, the chance that you receive $\$ 2.00$ is the smallest among the three possible money payments; the chance that you receive $\$ 7.00$ is twice as likely as $\$ 2.00$; the chance that you receive $\$ 5.00$ is four times as likely as $\$ 2.00$. Thus, the chance that you receive $\$ 5.00$ is twice as likely as $\$ 7.00$. Perhaps the following diagram helps you understand the lottery. In this diagram, the length of the bar indicates the likelihood of each payment. The longer the bar for the payment, the more likely the payment is.

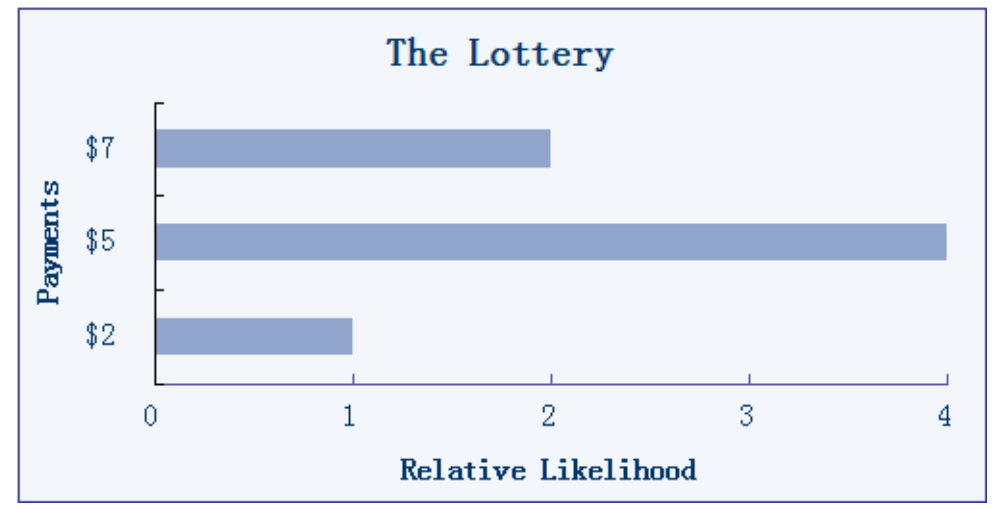

In case you choose the lottery you will be informed after your choice about which money payment of the lottery has occurred. 
In phase 2, you might see a choice represented like this:

\begin{tabular}{|c|c|c|c|}
\hline \multicolumn{3}{|c|}{ Lottery } & Sure money payment \\
\hline$\$ 3.00$ & $\$ 5.50$ & $\$ 8.00$ & \multirow[b]{2}{*}{$\$ 6.50$} \\
\hline $\begin{array}{l}2 \text { times as likely as } \\
\$ 5.50 \text { payment }\end{array}$ & & $\begin{array}{c}3 \text { times as likely as } \\
\$ 5.50 \text { payment }\end{array}$ & \\
\hline
\end{tabular}

Here you are still choosing between a lottery and a sure money payment. The difference is that you will be given a different lottery. If you choose the lottery then you might receive $\$ 3.00$, $\$ 5.50$, or $\$ 8.00$. Below each possible payment, we write how likely it is relative to the $\$ 2.00$ payment. For example, the chance that you receive $\$ 5.50$ is the smallest among the three possible money payments; the chance that you receive $\$ 3.00$ is twice as likely as $\$ 5.50$; the chance that you receive $\$ 8.00$ is three times as likely as $\$ 5.50$.

IMPORTANT NOTE: In ALL periods in phase 2, the actual lottery is EXACTLY THE SAME, both in terms of all the possible payments and how likely you might receive them.

Phase 3 is identical to phase 1.

At the end of the experiment you will be paid for one period only. This period will be selected randomly. The reward earned in this period will be paid to you privately immediately after the experiment together with the show up fee of $\$ 5.00$.

After finishing the experiment but before receiving the payment, you will need to fill in a questionnaire. In the questionnaire we will ask you to provide some demographic information about yourself. This questionnaire does not affect your payment. Moreover, data are collected anonymously so that privacy is respected. 


\section{Instructions}

Thank you for participating in this experiment. You will receive at least a $\$ 5.00$ show up fee for your participation. You can earn additional money with the choices you make in the experiment. So please read the following explanations carefully.

During the experiment you are not allowed to communicate with each other. If you have any questions please raise your hand. An experimenter will come to answer your questions.

The experiment consists of 3 phases, in each phase there are 16 periods. Altogether there are 48 periods. In each period you will choose between a lottery and a sure money payment. In each phase, the lottery is the same in all periods. However, the lotteries can be different between phases.

Here is an example of one period in phase 1:

\begin{tabular}{|c|c|c|}
\hline \multicolumn{3}{|c|}{ Lottery } \\
\hline$\$ 2.00$ & $\$ 5.00$ & $\$ 7.00$ \\
\hline & 4 times as likely as & 2 times as likely as \\
& $\$ 2.00$ payment & $\$ 2.00$ payment \\
\hline
\end{tabular}

\begin{tabular}{|c|}
\hline Sure money payment \\
\hline$\$ 4.50$ \\
\hline
\end{tabular}

In this example, if you choose the sure money payment you will receive $\$ 4.50$. If you choose the lottery then you might receive $\$ 2.00, \$ 5.00$, or $\$ 7.00$. Below each possible payment, we write how likely it is relative to the $\$ 2.00$ payment. For example, the chance that you receive $\$ 2.00$ is the smallest among the three possible money payments; the chance that you receive $\$ 7.00$ is twice as likely as $\$ 2.00$; the chance that you receive $\$ 5.00$ is four times as likely as $\$ 2.00$. Thus, the chance that you receive $\$ 5.00$ is twice as likely as $\$ 7.00$. Perhaps the following diagram helps you understand the lottery. In this diagram, the length of the bar indicates the likelihood of each payment. The longer the bar for the payment, the more likely the payment is.

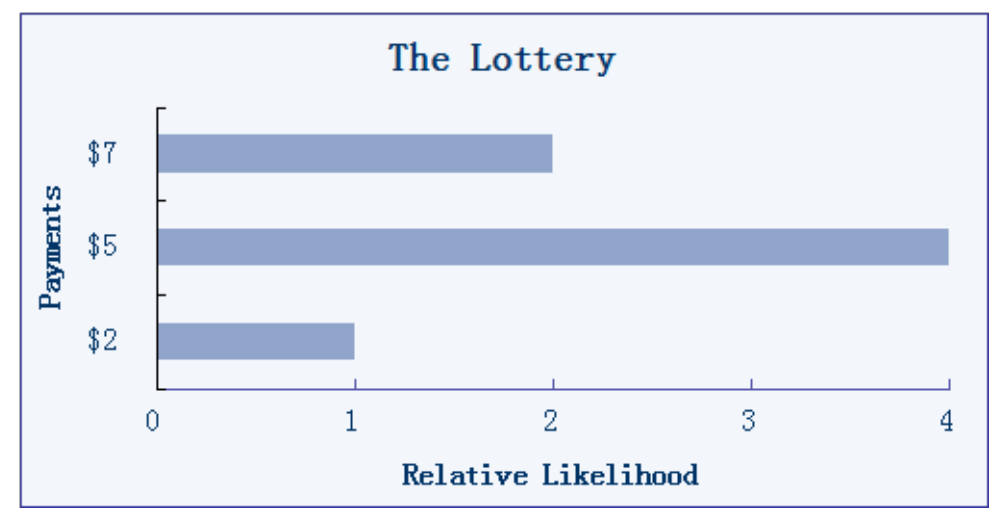

In case you choose the lottery you will be informed after your choice about which money payment of the lottery has occurred. 
In phase 2, you might see a choice represented like this:

\begin{tabular}{|c|c|c|}
\hline \multicolumn{3}{|c|}{ Lottery } \\
\hline$\$ 3.00$ & $\$ 5.50$ & $\$ 8.00$ \\
\hline 2 times as likely as & & 3 times as likely as \\
$\$ 5.50$ payment & & $\$ 5.50$ payment \\
\hline
\end{tabular}

\begin{tabular}{|c|}
\hline Sure money payment \\
\hline$\$ 6.50$ \\
\hline
\end{tabular}

In case you choose the lottery you will observe the realized payment immediately.

IMPORTANT NOTE: in ALL periods in phase 2, the actual lottery is EXACTLY THE SAME, both in terms of all the possible payments and how likely you might receive them relative to the least likely payment.

Phase 3 is identical to phase 1.

At the end of the experiment you will be paid for one period only. This period will be selected randomly. The reward earned in this period will be paid to you privately immediately after the experiment together with the show up fee of $\$ 5.00$.

After finishing the experiment but before payment, you will need to fill in a questionnaire. In the questionnaire we will ask you to provide some demographic information about yourself. This questionnaire does not affect your payment. Moreover, data are collected anonymously so that privacy is fully respected. 


\section{Instructions}

Thank you for participating in this experiment. You will receive at least a $\$ 5.00$ show up fee for your participation. You can earn additional money with the choices you make in the experiment. So please read the following explanations carefully.

During the experiment you are not allowed to communicate with each other. If you have any questions please raise your hand. An experimenter will come to answer your questions.

The experiment consists of 3 phases, in each phase there are 16 periods. Altogether there are 48 periods. In each period you will choose between a lottery and a sure money payment. In each phase, the lottery is the same in all periods. However, the lotteries can be different between phases.

Here is an example of one period in phase 1:

\begin{tabular}{|c|c|c|}
\hline \multicolumn{3}{|c|}{ Lottery } \\
\hline$\$ 2.00$ & $\$ 5.00$ & $\$ 7.00$ \\
\hline & 4 times as likely as & 2 times as likely as \\
& $\$ 2.00$ payment & $\$ 2.00$ payment \\
\hline
\end{tabular}

\begin{tabular}{|c|}
\hline Sure money payment \\
\hline$\$ 4.50$ \\
\hline
\end{tabular}

In this example, if you choose the sure money payment you will receive $\$ 4.50$. If you choose the lottery then you might receive $\$ 2.00, \$ 5.00$, or $\$ 7.00$. Below each possible payment, we write how likely it is relative to the $\$ 2.00$ payment. For example, the chance that you receive $\$ 2.00$ is the smallest among the three possible money payments; the chance that you receive $\$ 7.00$ is twice as likely as $\$ 2.00$; the chance that you receive $\$ 5.00$ is four times as likely as $\$ 2.00$. Thus, the chance that you receive $\$ 5.00$ is twice as likely as $\$ 7.00$. Perhaps the following diagram helps you understand the lottery. In this diagram, the length of the bar indicates the likelihood of each payment. The longer the bar for the payment, the more likely the payment is.

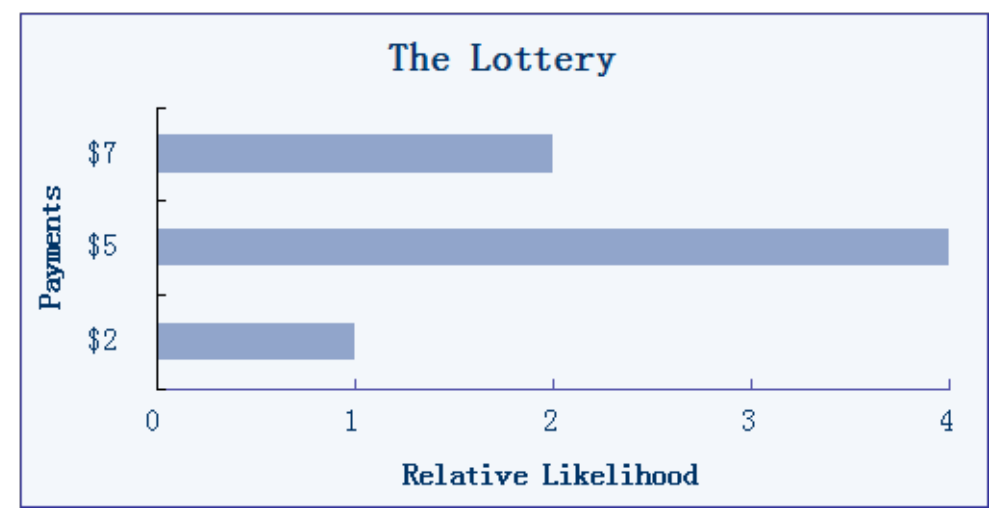

In case you choose the lottery you will be informed after your choice about which money payment of the lottery has occurred. 
In phase 2, you might see a choice represented like this:

\begin{tabular}{|c|c|c|}
\hline \multicolumn{3}{|c|}{ Lottery } \\
\hline$\$ 3.00$ & $\$ 5.50$ & $?$ \\
\hline $\begin{array}{c}\text { 2 times as likely as } \\
\$ 5.50 \text { payment }\end{array}$ & & $?$ \\
\hline
\end{tabular}

\begin{tabular}{|c|}
\hline Sure money payment \\
\hline$\$ 6.50$ \\
\hline
\end{tabular}

Here you are still choosing between a sure money payment and a lottery. The difference is some possible payment and how likely you might receive such payment are hidden. Each column with a question mark “?” represents one hidden possible payment. In case you choose the lottery you will observe the realized payment immediately. If a hidden payment occurs, you will learn immediately its value and how likely you might receive it relative to the least likely payment.

For example, if you choose the lottery and the hidden payment occurs, which in this example is $\$ 8.00$, then you will observe:

\begin{tabular}{|c|c|c|}
\hline \multicolumn{3}{|c|}{ Lottery } \\
\hline$\$ 3.00$ & $\$ 5.50$ & $\$ 8.00$ \\
\hline 2 times as likely as & & 3 times as likely as \\
$\$ 5.50$ payment & & $\$ 5.50$ payment \\
\hline
\end{tabular}

\begin{tabular}{|c|}
\hline Sure money payment \\
\hline$\$ 6.50$ \\
\hline
\end{tabular}

IMPORTANT NOTE: in ALL periods in phase 2, the actual lottery is EXACTLY THE SAME, both in terms of all the possible payments and how likely you might receive them. In addition, some hidden payments will be revealed to you over time. When this happens you will observe them on your screen.

Phase 3 is identical to phase 1.

At the end of the experiment you will be paid for one period only. This period will be selected randomly. The reward earned in this period will be paid to you privately immediately after the experiment together with the show up fee of $\$ 5.00$.

When you finish this experiment, you will need to fill in a questionnaire. In the questionnaire we will ask you to provide some general information about yourself. This questionnaire does not affect your payment. 


\section{Instructions}

Thank you for participating in this experiment. You will receive at least a $\$ 5.00$ show up fee for your participation. You can earn additional money with the choices you make in the experiment. So please read the following explanations carefully.

During the experiment you are not allowed to communicate with each other. If you have any questions please raise your hand. An experimenter will come to answer your questions.

The experiment consists of 3 phases, in each phase there are 16 periods. Altogether there are 48 periods. In each period you will choose between a lottery and a sure money payment. In each phase, the lottery is the same in all periods. However, the lotteries can be different between phases.

Here is an example of one period in phase 1:

\begin{tabular}{|c|c|c|}
\hline \multicolumn{3}{|c|}{ Lottery } \\
\hline$\$ 2.00$ & $\$ 5.00$ & $\$ 7.00$ \\
\hline & 4 times as likely as & 2 times as likely as \\
& $\$ 2.00$ payment & $\$ 2.00$ payment \\
\hline
\end{tabular}

\begin{tabular}{|c|}
\hline Sure money payment \\
\hline$\$ 4.50$ \\
\hline
\end{tabular}

In this example, if you choose the sure money payment you will receive $\$ 4.50$. If you choose the lottery then you might receive $\$ 2.00, \$ 5.00$, or $\$ 7.00$. Below each possible payment, we write how likely it is relative to the $\$ 2.00$ payment. For example, the chance that you receive $\$ 2.00$ is the smallest among the three possible money payments; the chance that you receive $\$ 7.00$ is twice as likely as $\$ 2.00$; the chance that you receive $\$ 5.00$ is four times as likely as $\$ 2.00$. Thus, the chance that you receive $\$ 5.00$ is twice as likely as $\$ 7.00$. Perhaps the following diagram helps you understand the lottery. In this diagram, the length of the bar indicates the likelihood of each payment. The longer the bar for the payment, the more likely the payment is.

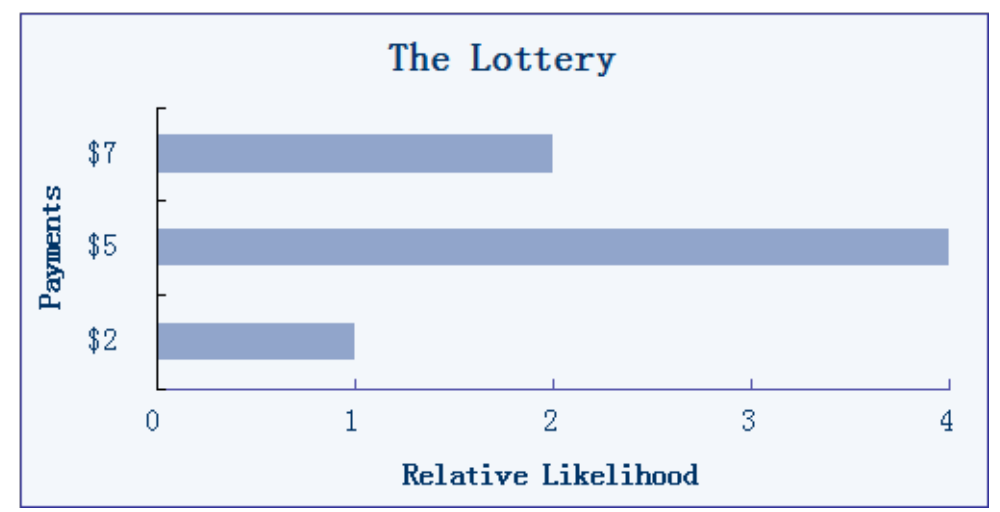

In case you choose the lottery you will be informed after your choice about which money payment of the lottery has occurred. 
In phase 2, you might see a choice represented like this:

\begin{tabular}{|l|l|}
\hline \multicolumn{2}{|c|}{ Lottery } \\
\hline$\$ 3.00$ & $? \ldots$ \\
\hline & $? \ldots$ \\
\hline
\end{tabular}

\begin{tabular}{|c|} 
Sure money payment \\
$\$ \$ 6.50$
\end{tabular}

Here you are still choosing between a sure money payment and a lottery. The difference is some possible payments and how likely you might receive such payments are hidden. Each column of the question mark "?..." represents some hidden possible payments or how likely you might receive them. How many possible payments there are in total is hidden. In case you choose the lottery you will observe the realized payment immediately. If a hidden payment occurs, you will learn its value and how likely you might receive it relative to the least likely payment.

For example, if you choose the lottery and the hidden payment occurs, which is $\$ 3.00$, then you will observe it as a possibility afterwards:

\begin{tabular}{|c|c|c|}
\hline \multicolumn{3}{|c|}{ Lottery } \\
\hline$\$ 3.00$ & $\$ 5.50$ & $? \ldots$ \\
\hline $\begin{array}{c}\text { 2 times as likely as } \\
\$ 5.50 \text { payment }\end{array}$ & & $? \ldots$ \\
\hline
\end{tabular}

\begin{tabular}{|c|}
\hline Sure money payment \\
\hline$\$ 6.50$ \\
\hline
\end{tabular}

IMPORTANT NOTE: in ALL periods in phase 2, the actual lottery is EXACTLY THE SAME, both in terms of all the possible payments and how likely you might receive them. In addition, some hidden payments will be revealed to you over time. When this happens you will observe them on your screen.

Phase 3 is identical to phase 1.

At the end of the experiment you will be paid for one period only. This period will be selected randomly. The reward earned in this period will be paid to you privately immediately after the experiment together with the show up fee of $\$ 5.00$.

When you finish this experiment, you will need to fill in a questionnaire. In the questionnaire we will ask you to provide some general information about yourself. This questionnaire does not affect your payment. 


\section{Instructions}

Thank you for participating in this experiment. You will receive at least a $\$ 5.00$ show up fee for your participation. You can earn additional money with the choices you make in the experiment. So please read the following explanations carefully.

During the experiment you are not allowed to communicate with each other. If you have any questions please raise your hand. An experimenter will come to answer your questions.

The experiment consists of 3 phases, in each phase there are 16 periods. Altogether there are 48 periods. In each period you will choose between a lottery and a sure money payment. In each phase, the lottery is the same in all periods. However, the lotteries can be different between phases.

Here is an example of one period in phase 1:

\begin{tabular}{|c|c|c|}
\hline \multicolumn{3}{|c|}{ Lottery } \\
\hline$\$ 2.00$ & $\$ 5.00$ & $\$ 7.00$ \\
\hline & 4 times as likely as & 2 times as likely as \\
& $\$ 2.00$ payment & $\$ 2.00$ payment \\
\hline
\end{tabular}

\begin{tabular}{|c|}
\hline Sure money payment \\
\hline$\$ 4.50$ \\
\hline
\end{tabular}

In this example, if you choose the sure money payment you will receive $\$ 4.50$. If you choose the lottery then you might receive $\$ 2.00, \$ 5.00$, or $\$ 7.00$. Below each possible payment, we write how likely it is relative to the $\$ 2.00$ payment. For example, the chance that you receive $\$ 2.00$ is the smallest among the three possible money payments; the chance that you receive $\$ 7.00$ is twice as likely as $\$ 2.00$; the chance that you receive $\$ 5.00$ is four times as likely as $\$ 2.00$. Thus, the chance that you receive $\$ 5.00$ is twice as likely as $\$ 7.00$. Perhaps the following diagram helps you understand the lottery. In this diagram, the length of the bar indicates the likelihood of each payment. The longer the bar for the payment, the more likely the payment is.

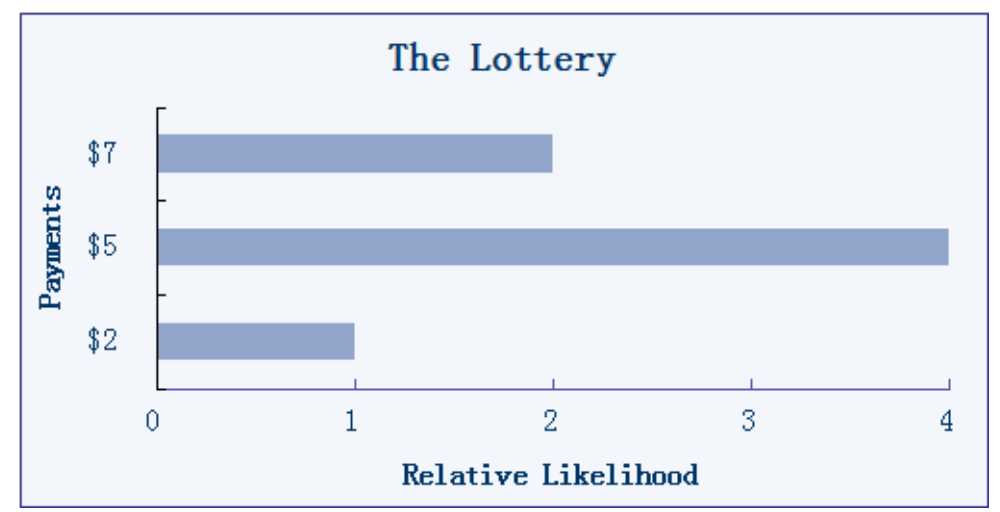

In case you choose the lottery you will be informed after your choice about which money payment of the lottery has occurred. 
In phase 2, you might see a choice represented like this:

\begin{tabular}{|c|c|c|}
\hline \multicolumn{3}{|c|}{ Lottery } \\
\hline$\$ 3.00$ & $\$ 5.50$ & $\$ 8.00$ \\
\hline $\begin{array}{c}\text { 2 times as likely as } \\
\$ 5.50 \text { payment }\end{array}$ & & $?$ \\
\hline
\end{tabular}

\begin{tabular}{|c|}
\hline Sure money payment \\
\hline$\$ 6.50$ \\
\hline
\end{tabular}

Here you are still choosing between a lottery and a sure money payment. The difference is that the information on how likely you might receive the payment $\$ 8.00$ is hidden.

IMPORTANT NOTE: in ALL periods in phase 2, the actual lottery is EXACTLY THE SAME, both in terms of all the possible payments and how likely you might receive them.

Phase 3 is identical to phase 1.

At the end of the experiment you will be paid for one period only. This period will be selected randomly. The reward earned in this period will be paid to you privately immediately after the experiment together with the show up fee of $\$ 5.00$.

When you finish this experiment, you will need to fill in a questionnaire. In the questionnaire we will ask you to provide some general information about yourself. This questionnaire does not affect your payment. 


\section{A.2 Questionnaire}

Session ID:

Terminal No.:

\section{Questionnaire}

Below questions are very important to our research.

1. What is your gender? $\square$ Male $\square$ Female

2. What's your age?

3. What is your racial background? Check all applicable.

White $\square$ Asian $\square$ Hispanic $\square$ Black/African Am. $\square$ Other

4. Which languages do you speak?

5. How fluent are you in English?
Native
Fluent
Basic
Least

6. Are you currently a student?

$\square$ Yes

No

7. What are your majors of study?

8. What is your current GPA?

9. Have you taken a course in microeconomics? $\square$ Yes $\square$ No

10. Have you taken a course in game theory, decision making, or economics of uncertainty? $\square$ Yes $\quad \square$ No

11. Did you ever play in a casino? $\square$ Yes $\quad \square$ No 
15. How do you see yourself? Are you generally a person who is fully prepared to take risks or do you try to avoid taking risks? Please check a box on below scale, where the value 0 means 'not at all willing to take risks' and the value 10 means 'very willing to take risks'.

$\begin{array}{ccccccccccc}\square & \square & \square & \square & \square & \square & \square & \square & \square & \square & \square \\ 0 & 1 & 2 & 3 & 4 & 5 & 6 & 7 & 8 & 9 & 10 \\ \begin{array}{c}\text { Not at } \\ \text { all }\end{array} & & & & & & & & & & \text { Very } \\ \begin{array}{c}\text { willing } \\ \text { to take } \\ \text { risks }\end{array} & & & & & & & & & & \\ \text { willing } \\ \text { to take } \\ \text { risks }\end{array}$

16. How do you see yourself? Are you generally a person who embraces novel things or do you hesitate to adopt novelties? Please check a box on the scale, where the value 0 means `not at all willing to adopt novelties' and the value 10 means `very willing to adopt novelties'.

$\begin{array}{ccccccccccc}\square & \square & \square & \square & \square & \square & \square & \square & \square & \square & \square \\ 0 & 1 & 2 & 3 & 4 & 5 & 6 & 7 & 8 & 9 & 10 \\ \begin{array}{c}\text { Not at } \\ \text { all }\end{array} & & & & & & & & & & \text { Very } \\ \text { willing } \\ \text { to adopt } \\ \text { novelties }\end{array}$




\section{A.3 Screenshots}

Figure 1 shows the lottery and the sure payment in phases 1 and 3. Participants needed to make a choice on this page. If the lottery was chosen, Figure 2 displays the realized outcome of the lottery as the reward of that period.

Figure 1: Choice between the lottery and the sure payment

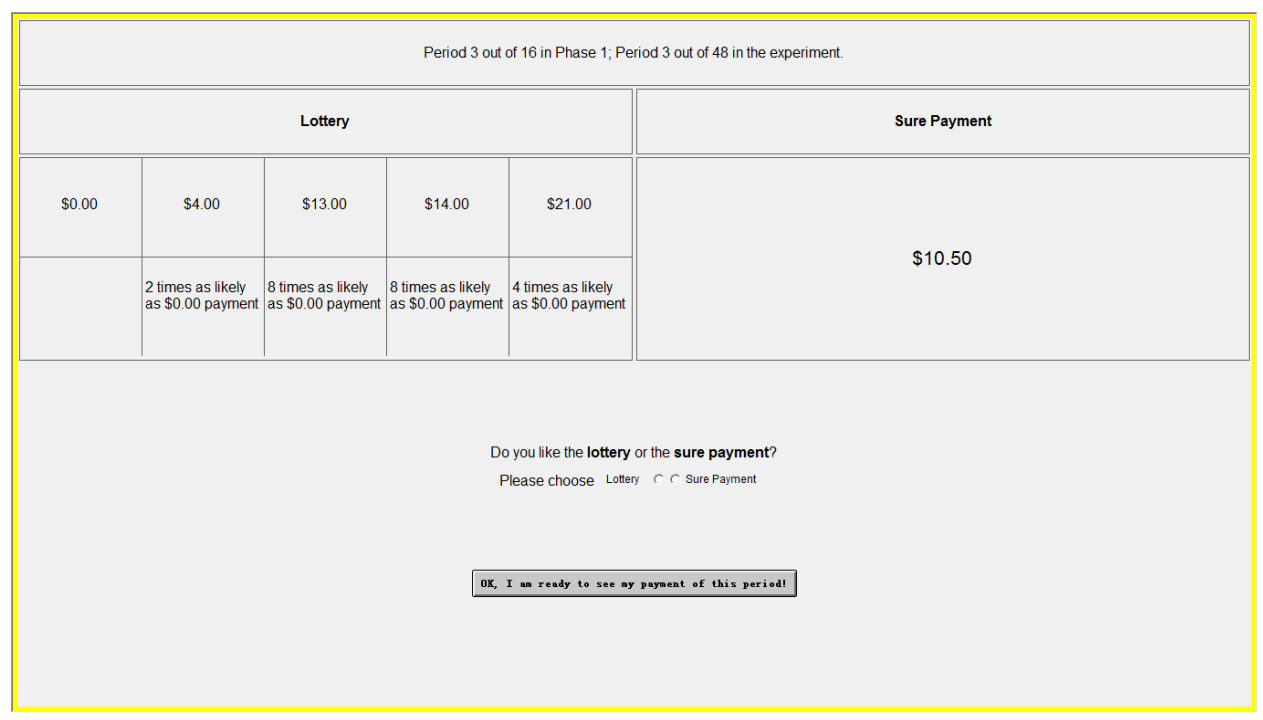

Figure 2: Realization of the lottery if the lottery was chosen

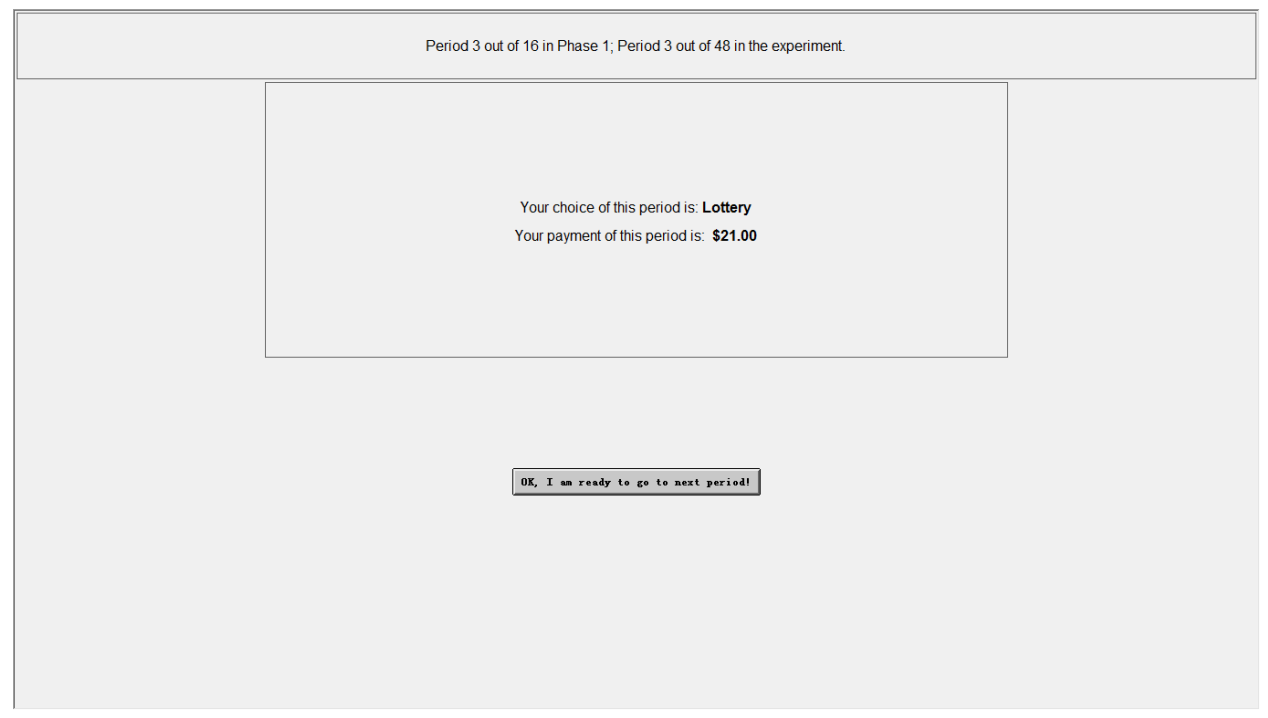

Figure 3 displays the choice of a period in Treatment U. Figure 4 is the screen displayed 
to participants if the lottery was chosen and a hidden outcome $\$ 0.00$ was realized. After that, the outcome $\$ 0.00$ and its relative likelihood were always displayed in the lottery, shown in Figure 5 .

Figure 3: Choice displayed in Treatment U

\begin{tabular}{|c|c|c|c|}
\hline \multicolumn{4}{|c|}{ Period 1 out of 16 in Phase 2; Period 17 ou of 48 in the experiment. } \\
\hline \multicolumn{3}{|c|}{ Lottery } & Sure Payment \\
\hline$\$ 14.00$ & $\$ 20.00$ & $\$ 25.00$ & \multirow{2}{*}{$\$ 15.00$} \\
\hline $\begin{array}{l}12 \text { times as likely as } \$ 25.00 \\
\text { payment }\end{array}$ & $\begin{array}{l}12 \text { tmes as likely as } \$ 25.00 \\
\text { payment }\end{array}$ & & \\
\hline \multicolumn{4}{|c|}{$\begin{array}{l}\text { Do you like the lottery or the sure payment? } \\
\text { Please choose Lotery } C \subset \text { Sure payment }\end{array}$} \\
\hline \multicolumn{4}{|c|}{ OK. I an ready to see my pasment of this peri od! } \\
\hline
\end{tabular}

Figure 4: When a new outcome of the lottery was play out

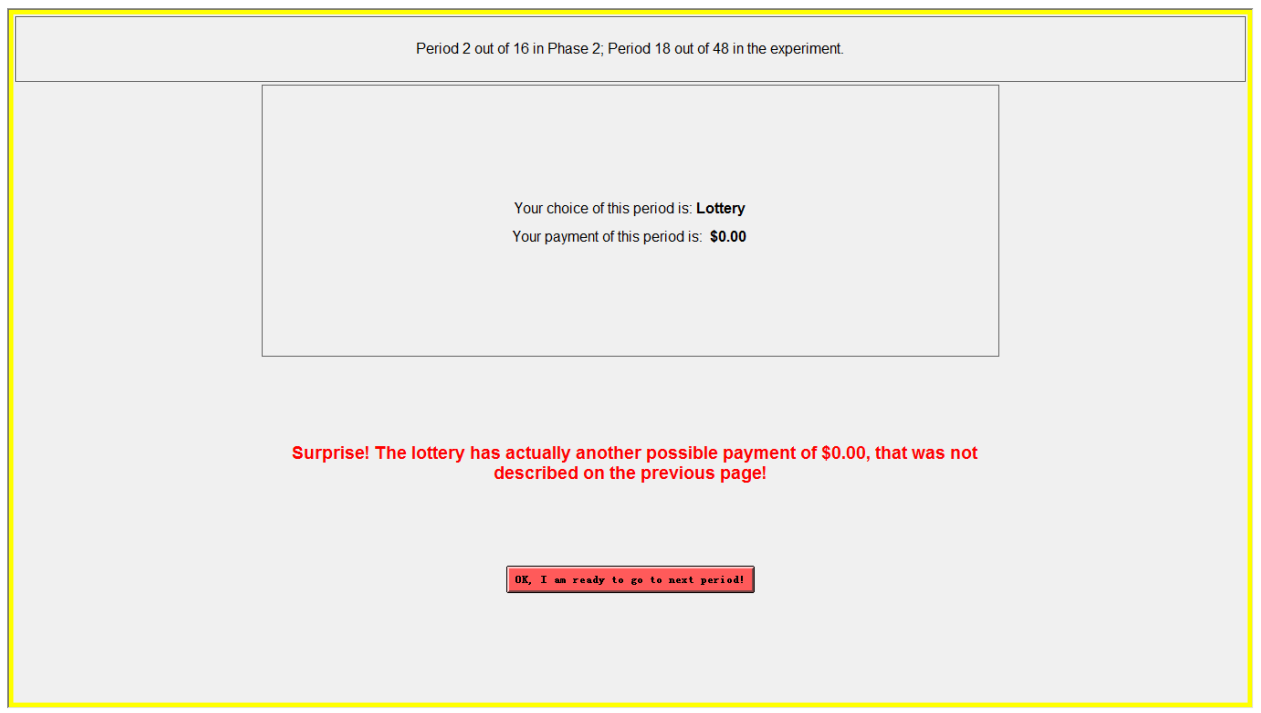


Figure 5: After the realization of such new outcome

\begin{tabular}{|c|c|c|c|c|}
\hline \multicolumn{5}{|c|}{ Period 3 out of 16 in Phase 2 ; Period 19 out of 48 in the experiment. } \\
\hline \multicolumn{4}{|c|}{ Lottery } & Sure Payment \\
\hline$\$ 0.00$ & $\$ 14.00$ & $\$ 20.00$ & $\$ 25.00$ & \multirow{2}{*}{$\$ 11.50$} \\
\hline $\begin{array}{l}6 \text { times as ikely as } \\
\$ 25.00 \text { payment }\end{array}$ & $\begin{array}{l}12 \text { times as likely as } \\
\$ 25.00 \text { payment }\end{array}$ & $\begin{array}{l}12 \text { times as likely as } \\
\$ 25.00 \text { payment }\end{array}$ & & \\
\hline \multicolumn{5}{|c|}{$\begin{array}{l}\text { Do you like the lottery or the sure payment? } \\
\text { Please choose Lottery } C \sim \text { Sure Payment }\end{array}$} \\
\hline \multicolumn{5}{|c|}{ OK. I am ready to see my pasment of this peri iod! } \\
\hline
\end{tabular}

Figure 6: Lottery displayed in Treatment AU1 in a period of phase 2

\begin{tabular}{|c|c|c|c|c|}
\hline \multicolumn{3}{|c|}{ Lottery } \\
\hline \hline$\$ 14.00$ & $\$ 20.00$ & $\$ 25.00$ & $?$ & $?$ \\
\hline $\begin{array}{l}12 \text { times as likely } \\
\text { as } \begin{array}{l}\hline \multicolumn{2}{|c|}{\text { payment }} \\
\text { payment }\end{array}\end{array}$ & $\begin{array}{l}12 \text { times as likely } \\
\text { as } \\
\text { payment }\end{array}$ & & $?$ & $?$ \\
\hline
\end{tabular}

Figure 7: Lottery displayed in Treatment AU2 in a period of phase 2

\begin{tabular}{|c|c|c|c|}
\hline \multicolumn{2}{|c|}{ Lottery } \\
\hline \hline$\$ 14.00$ & $\$ 20.00$ & $\$ 25.00$ & $? \ldots$ \\
\hline $\begin{array}{l}12 \text { times as likely as } \\
\$ 25.00 \text { payment }\end{array}$ & $\begin{array}{l}12 \text { times as likely as } \\
\$ 25.00 \text { payment }\end{array}$ & & $? \ldots$ \\
\hline
\end{tabular}


Figure 8: Lottery displayed in Treatment $\mathrm{A}$ in a period of phase 2

\begin{tabular}{|c|c|c|c|c|}
\hline \multicolumn{2}{|c|}{ Lottery } \\
\hline \hline$\$ 0.00$ & $\$ 8.00$ & $\$ 14.00$ & $\$ 20.00$ & $\$ 25.00$ \\
\hline$?$ & $?$ & $\begin{array}{l}12 \text { times as likely } \\
\text { as } \$ 25.00 \\
\text { payment }\end{array}$ & $\begin{array}{l}12 \text { times as likely } \\
\text { as } \$ 25.00 \\
\text { payment }\end{array}$ & \\
\hline
\end{tabular}

Table 8: Probit Regression of Consistency Across Treatments

\begin{tabular}{|c|c|c|c|c|}
\hline & $\mathrm{c} 1$ & $\mathrm{c} 2$ & c3 & $\mathrm{c} 4$ \\
\hline \multirow[t]{2}{*}{ Unawareness } & -0.0035 & -0.0205 & 0.0479 & 0.0557 \\
\hline & $(0.1864)$ & $(0.1982)$ & $(0.1901)$ & $(0.1983)$ \\
\hline \multirow[t]{2}{*}{ Awareness of unawareness 1} & 0.1148 & 0.1505 & 0.1580 & 0.1803 \\
\hline & $(0.1887)$ & $(0.2041)$ & $(0.1892)$ & $(0.2043)$ \\
\hline \multirow[t]{2}{*}{ Awareness of unawareness 2} & -0.0168 & 0.0587 & -0.1293 & -0.0838 \\
\hline & $(0.1838)$ & $(0.1946)$ & $(0.1910)$ & $(0.1959)$ \\
\hline \multirow[t]{2}{*}{ Ambiguity } & -0.0931 & -0.0537 & -0.1414 & -0.0567 \\
\hline & $(0.1869)$ & $(0.1992)$ & $(0.1954)$ & $(0.2024)$ \\
\hline Questionnaire Controls & No & Yes & No & Yes \\
\hline $\begin{array}{l}\text { Number of Observations } \\
\mathrm{R}^{2}\end{array}$ & 437 & 427 & 437 & 427 \\
\hline
\end{tabular}


Figure 9: Scatter Plot of Approx. Certainty Equivalents in Phases 1 and 3
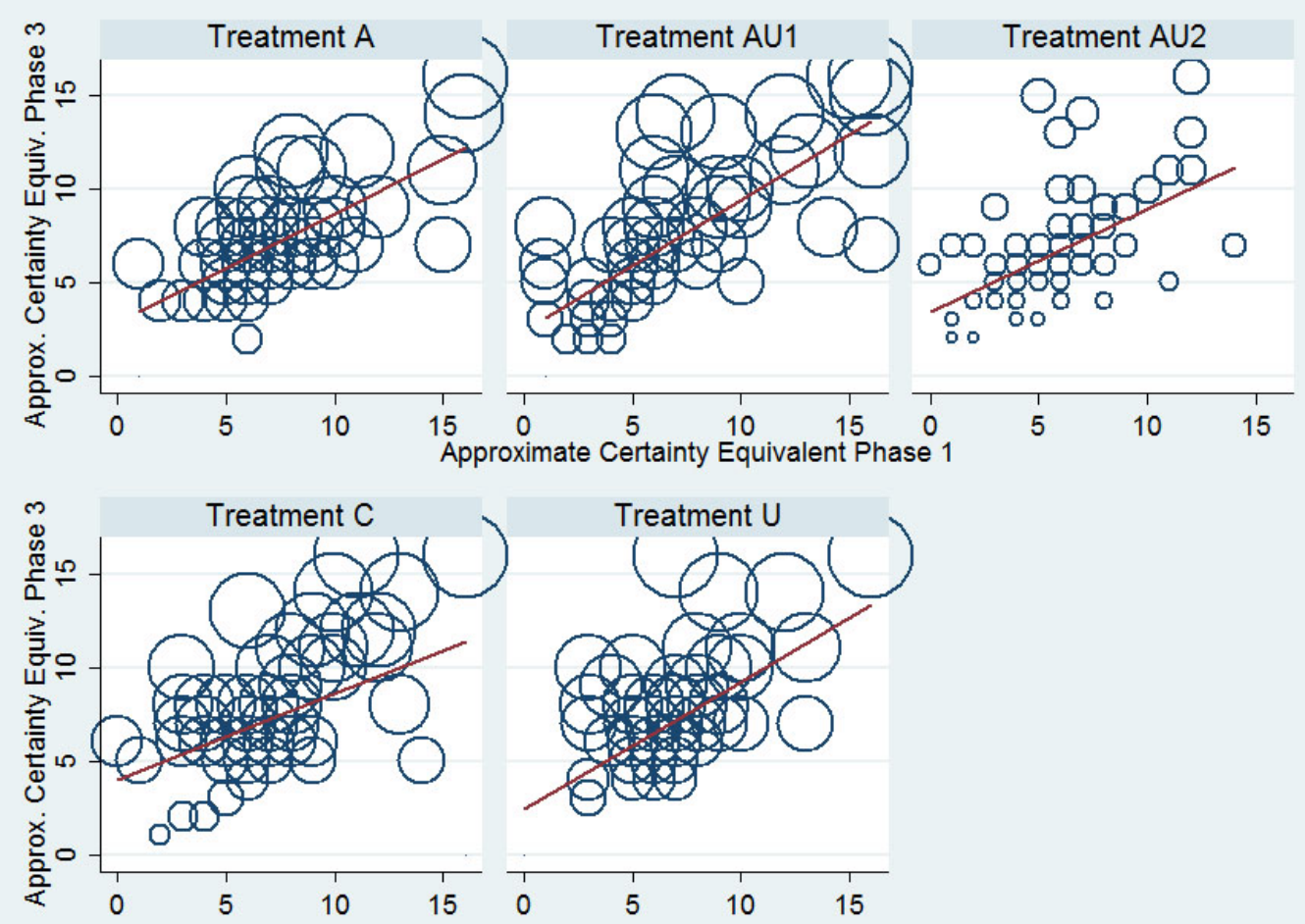